\title{
Pengaruh Density Gulungan Benang Dan Waktu Proses Pencelupan Terhadap Kerataan Warna Hasil Pencelupan Benang Kapas Dengan Zat Warna Reaktif Cara Perendaman
}

\author{
Sri Yanti ${ }^{1)}$, Hardjito S. Darmojo ${ }^{2)}$, Dine Agustine ${ }^{3 *}$ \\ Jurusan Teknik Kimi, Fakultas Teknik, Universitas Islam Syekh Yusuf, Jl. Mulana Yusuf No.10 Tangerang Banten \\ 15118, Indonesia \\ 1) sri yanti 08@yahoo.co.id \\ 2) hardjito_sd@yahoo.co.id \\ 3) dine.agustine.eka@gmail.com
}

\begin{abstract}
Abstrak. Density Gulungan Benang dan Waktu Proses Pencelupan Berpengaruh Terhadap Kerataan Warna Hasil Pencelupan Benang Kapas Dengan Zat Warna Reaktif Cara Perendaman. Tujuan untuk mengetahui pengaruh density gulungan benang dan waktu proses pencelupan terhadap kerataan warna hasil pencelupan benang kapas dengan zat warna reaktif cara peremdaman. Metodologi penelitian dengan metode eksperimen, kombinasi perlakuan. Faktor A : density gulungan benang, $\left(\mathrm{gr} / \mathrm{cm}^{3}\right), a_{1}: 0.28, a_{2}: 0.32, a_{3}: 0.36$, dan Faktor $B:$ waktu proese pencelupan In-Out / Out-In, (menit), $b_{1}$ : In-Out 1 / Out-In 2, $b_{2}$ : In-Out $2 /$ Out-In 3, $b_{3}:$ In-Out 3 / Out-In 3, dengan pengulangan tiga kali pada masing-masing kombinasi perlakuan. Hasil penelitian : density gulungan benang $0.32 \mathrm{gr} / \mathrm{cm}^{3}$, menunjukkan hasil terbaik dalam hal kerataan warna, ditunjukkan oleh nilai perbedaan warna $(D E c m c=0.143)$, hasil uji dengan alat spektrofotometri, dan uji hipotesis dengan $F_{\text {hit }}(16.85)>F_{\text {tab }}$ (4.75), dan waktu proses pencelupan (in : 2 menit / out : 3 menit), menunjukkan hasil terbaik kerataan warnanya ditunjukkan oleh nilai perbedaan warna DEcmc $=0.143)$, dan hasil uji $F_{\text {hit }}(18.12)>F_{\text {tab }}$ (3.88). Hasil penelitian menunjukkan bahwa density gulungan benang 0.32 $\mathrm{gr} / \mathrm{cm} 3$, dan waktu proses pencelupan (in : 2 menit / out : 3 menit), menunjukkan kerataan warna ditunjukkan oleh $($ Decmc $=0.143)$, dan uji $F_{\text {hit }}(13.56)>F_{\text {tab }}$ (3.88). Kesimpulan hasil penelitian : density gulungan benang dan waktu proses pencelupan benang berpengaruh terhadap kerataan warna hasil pencelupan benang kapas dengan zat warna reaktif cara perendaman.
\end{abstract}

Kata kunci: Density yarn winder, dyeing time, reactive dyes

\begin{abstract}
THE INFLUENCE OF DENSITY YARN WINDER AND DYEING TIME ON THE FLATNESS OF COLOUR COTTON YARN WITH REACTIVE DYES. This research aims to find out the influence of density yarn winder and dyeing time on the flatness of colour cotton yarn dyeing with reactive dyes uses exhaustion process. Experimental method with treatment combination was used in this reseach. A factor, density of yarn winder $\left(\mathrm{gr} / \mathrm{cm}^{3}\right), a_{1}: 0.28, a_{2}: 0.32, a_{3}: 0.36$, and B factor : dyeing time, In-Out / Out-In, (menit), $b_{1}$ : In-Out 1 / Out-In 2, $b_{2}$ : In-Out 2 / Out-In 3, $b_{3}$ $\therefore$ In-Out 3 / Out-In 3, with three times replication on each treatment combination

The research result found that $0.32 \mathrm{gr} / \mathrm{cm}^{3}$ density of yarn winder showed best result in colour flatness indicated by colour difference value $(D E c m c=0.143)$ using spectrophotometry testing and result of hypothesis $F_{\text {Count }}(16.85)>F_{\text {table }}$ (4.75), and the best dyeing time (in : 2 menit / out : 3 menit) showed the best flatness of colour indicated by colour difference value (DEcmc $=0.143)$, using spectrophotometry testing and result of hypothesis $F_{\text {Count }}(18.12)>F_{\text {table }}(3.88)$. The conclusion of the result show thread density of yarn winder and dyeing time influence to the colour flatness of cotton yarn with reactive dyes exhausting method.
\end{abstract}

Keyword : Density yarn winder, dyeing time, reactive dyes

\section{Pendahuluan}

Meningkatnya konsumsi tekstil dunia yang berasal dari selulosa terutama kapas mencapai $40 \%$ berdampak pada zat warna yang digunakan untuk memberikan warna baik dalam bentuk serat, benang maupun kain. Dari semua zat warna yang digunakan untuk mencelup bahan tekstil, hampir 5\% menggunakan zat warna reaktif, karena hasil celupan 


\section{Jurnal Keilmuan dan Aplikasi Teknik \\ UNISTEK, 2018, Edisi 5, No.1}

dengan zat warna reaktif mempunyai ketahana luntur warna yang baik. karena zat warna dapat mengadakan reaksi dengan serat sehingga zat warna merupakan bagian dari serat.

Tekstil merupakan salah satu primadona ekspor non migas Indonesia, sebagai penghasil devisa yang cukup besar ini menghadapi tantangan yang semakin berat, terutama dengan diberlakukannya kebijakan pasar bebas. Dalam menghadapi persaingan produk industri yang semakin meningkat seiring dengan tuntutan pasar, maka hanya produk yang unggul, mampu bersaing, berkualitas dan menarik konsumen serta biaya produk effisien yang akan mampu bertahan dan tetap bisa menjalankan kegiatannya serta dapat berkembang. Namun untuk mewujudkan sebuah produk yang unggul tidaklah mudah, sehingga penelitian dibidang ilmu dan teknologi yang berkaitan dengan produk tersebut sangat diperlukan. Seperti halnya pada pencelupan benang kapas yang dicelup dalam bentuk gulungan dalam cone.

Pasaran dunia akan dibanjiri oleh produkproduk dari berbagai negara yang bersaing secara bebas menurut mekanisme pasar, konsumen akan menempati posisi yang lebih kuat karena begitu banyaknya produk yang beredar, baik macam, kuantitas, kualitas maupun harganya. Keragaman itu memberikan kesempatan bagi konsumen untuk leluasa memilih. Demikian pula dalam memilih hasil celupan benang kapas.

Banyak faktor yang dapat menyebabkan tidak ratanya hasil pencelupan benang kapas dalam bentuk gulungan yang dicelup dengan zat warna reaktif cara perendaman. Kalau ditelusuri, setidaknya ada dua faktor yang berpotensi mempengaruhi terhadap kerataan hasil pencelupan benang kapas dalam bentuk gulungan yang dicelup dengan zat warna reaktif cara perendaman.

Pertama, density gulungan benang, makin tinggi density, gulungan benang akan semakin padat, sehingga makin sulit larutan celup meresap ke dalam gulungan benang dan selanjutnya kedalam serat pada benang ( benang terdiri dari kumpulan serat, serat terdiri atas molekul-molekul).

Kedua, waktu proses pencelupan, makin lama, (sampai batas tertentu, molekul serat yang dapat bereaksi dengan zat warna jumlahnya tertentu) maka makin lama kesempatan zat warna untuk meresap ke dalam gulungan benang, selanjutnya kedalam serat, sehingga kesempatan untuk bermigrasinya zat warna dalam molekul serat makin lama, sehingga hasil celupan akan makin rata.

\section{Rumusan Masalah}

Permasalahan yang ada dapat dirumuskan sebagai berikut :

1. Density gulungan benang kapas berpengaruh terhadap kerataan warna hasil pencelupan benang yang dicelup dengan zat warna reaktif cara perendaman.
2. Waktu proses pencelupan berpengaruh terhadap kerataan warna hasil Pencelupan benang yang dicelup dengan zat warna reaktif cara perendaman.

3. Terdapat interaksi density gulungan benang kapas dan waktu proses pencelupan yang akan berpengaruh terhadap kerataan warna hasil pencelupan benang yang dicelup dengan zat warna reaktif cara perendaman.

\section{Tujuan penelitian}

1. Untuk mengetahui Density gulungan benang kapas yang tepat sehingga hasil pencelupan benang yang dicelup dengan zat warna reaktif cara perendaman menghasilkan kerataan warna yang baik.

2. Untuk mengetahui waktu proses pencelupan benang yang efisien untuk menghasilkan kerataan warna yang baik.

3. Dapat memberikan manfaat baik teoritis maupun praktis, secara teori kontribusi keilmuan dibidang kajian teknologi pencelupan benang yang berkaitan dengan density dan waktu proses pencelupan, sedangkan secara praktis membantu memecahkan permasalahan yang dihadapi oleh produsen.

\section{Density Gulungan Benang Kapas}

Serat kapas terdiri dari rantai molekul selulosa yang tersusun kearah panjang serat, berselang seling dengan bagian kristalin dan amorf. Morfologi serat kapas secara membujur seperti pita yang terpuntir, sedang secara melintang seperti buah ginjal, serat kapas terdiri dari lapisan dinding primer, dinding skunder dan dinding lumen.

Sifat fisika serat kapas, warna kapas biasanya sedikit cream, karena pengaruh cuaca yang lama, debu-debu dan kotoran menyebabkan warna akan menjadi keabu-abuan, kekuatan serat kapas sangat dipengaruhi oleh kadar selulosa dalam serat, panjang rantai dan orientasinya, serat dalam keadaan basah kekuatan akan makin tinggi.

Sifat kimia serat kapas, serat selulosa kapas tersusun atas selulosa, maka sifat-sifat kimia serat kapas adalah sifat-sifat kimia selulosa. Serat kapas pada umumnya tahan terhadap alkali, tahan kondisi penyimpanan, pengolahan dan pemakain normal tetapi beberapa zat pengoksidasi atau penghidrolisa seperti asam menyebabkan kerusakan dengan akibat penurunan kekuatan serat.

Penurunan kekuatan serat kapas disebabkan oleh beberapa zat sebagai berikut : Asam menyababkan hidrolisa ikatan-ikatan glukosa dalam rantai selulosa menjadi hidroselulosa , Oksidator akan mengoksidasi selulosa menjadi oksiselulosa, Alkali kuat dengan konsentrasi tinggi menyebabkan penggelembungan, Jamur dan hama dapat memutus rantai-rantai selulosa, dan Kupromonium Hidroksida dapat melarutkan serat.

Benang tekstil tersusun dari serat-serat staple atau filamen, baik yang berasal dari alam maupun sintesis, yang disatukan atau diberi antihan untuk 


\section{Jurnal Keilmuan dan Aplikasi Teknik \\ UNISTEK, 2018, Edisi 5, No.1}

pembuatan kain tenun, kain rajut dan lain-lain. Macam-macam benang dibuat tergantung dari macam serat yang digunakan seperti : tekstur, pegangan, dan kelembutan kain yang akan dibuat. Terdapat bermacam-macam benang tekstil, antara lain klasifikasi berdasarkan jenis serat, cara pembuatan dan fungsi. Klasifikasi menurut penggunaannya : benang jahit, benang tenun, benang rajut. Benang tenun ada 2 macam : benang pakan dan benang lusi

Tiap benang tekstil memiliki sifat khusus masing-masing tergantung dari jenis serat, cara pembuatan dan fungsinya. Berdasarkan strukturnya dapat digolongkan menjadi : benang pintal, benang staple, benang single, benang gintir, benang tali, benang-benang kabel benang mono filamen, benang multi filamen, benang hias, benang tekstur, benang tanpa antihan. Mutu benang ditentukan dari kerataan, kenampakan dan kekuatan benang.

Density gulungan benang, biasa disebut sebagai kerapatan atau kepadatan, dalam hal ini merupakan kerapatan gulungan benang pada metal cone berbentuk seperti kerucut terpotong, kerapatan atau kepadatan gulungan benang dapat dihitung dengan terlebih dahulu mengetahui berat gulungan serta luas permukaan gulungan, sehingga dapat diketahui volume gulungan benang tersebut, makin tinggi density, gulungan benang akan semakin rapat atau padat, sehingga makin sulit larutan celup meresap ke dalam gulungan benang dan selanjutnya kedalam serat pada benang ( benang terdiri dari kumpulan serat, serat terdiri atas molekul-molekul), dan sebaliknya makin rendah density gulungan benang akan semakin mudah larutan celup meresap kedalam gulungan benang, namun ada dampak lain apabila density gulungan benang rendah yaitu gulungan benang akan rusak pada saat proses pencelupan dengan tekanan yang tinggi, untuk itu diperlukan atau dicari density yang ideal, sehingga hasil celupan baik tetapi benang tidak rusak.

Density dapat dicari dengan cara menghitung dengan rumus sebagai berikut:

Calculation for Density (Perhitungan density benang ) :

$$
\begin{gathered}
\text { Density }(\mathrm{gr} / \mathrm{cm})^{3}=\frac{\text { weight of } \operatorname{Yarn}(\mathrm{g})}{\text { Volume of } \operatorname{Yarn}\left(\mathrm{cm}^{3}\right)}=\frac{W}{V} \\
\mathrm{~W}=\mathrm{W}_{1}-\mathrm{W}_{2} \\
V=\frac{\pi h}{4} x\left[\frac{\left(D_{1}+d_{1}\right)^{2}}{2} x \frac{\left(D_{2}+d_{2}\right)^{2}}{2}\right]
\end{gathered}
$$

$\mathrm{W}:$ Net Weight of Yarn

$\mathrm{W}_{1}$ : Gross Weight of Take-up Pankage

$\mathrm{W}_{2}$ : Weight of Take-up Tube

$\mathrm{V}$ : Volume of Part

D : Diameter cones button

D : Diameter cones upper

$\mathrm{H}$ : height yarn

\section{Zat warna reaktif}

Pada tahun 1876 Witt menyatakan bahwa molekul zat warna merupakan gabungan dari zat organik yang tidak jenuh, kromofor sebagai pembawa warna dan auksokrom sebagai pengikat antara warna dengan serat. Zat organik tak jenuh umumnya berasal dari senyawa aromatik dan derivatifnya (benzene, toluene, xilena, naftalena, antrasena, dan sebagainya.), Fenol dan derivatifnya (fenol, orto/ meta/ para kresol, dan sebagainya.), senyawa mengandung nitrogen (piridina, kinolina, korbazolum, dan sebagainya). (Pratikto, 2003).

Kromofor merupakan zat pemberi warna yang berasal dari radikal kimia, seperti kelompok nitroso ($\mathrm{NO})$, nitro $\left(-\mathrm{NO}_{2}\right)$, azo $(-\mathrm{N}=\mathrm{N})$, etilena $(>\mathrm{C}=\mathrm{C}<)$, karbonil $(>\mathrm{C}=\mathrm{O})$, karbon nitrogen $(>\mathrm{C}=\mathrm{NH}$ dan $\mathrm{CH}=\mathrm{N}-)$, belerang $(>\mathrm{C}=\mathrm{S}$ dan $->\mathrm{C}-\mathrm{S}-\mathrm{S}-\mathrm{C}<)$. (Sastrawijaya, 1991).

Auksokrom merupakan gugus yang dapat meningkatkan daya kerja khromofor sehingga optimal dalam pengikatan. Auksokrom terdiri dari golongan kation yaitu $-\mathrm{NH}_{2}$, $-\mathrm{NH} \mathrm{Me}$, - N $\mathrm{Me}_{2}$ seperti ${ }^{+} \mathrm{NMe}_{2} \mathrm{Cl}^{-}$, golongan anion yaitu $\mathrm{SO}_{3} \mathrm{H}-,-\mathrm{OH},-\mathrm{COOH}$. Auksokrom juga merupakan radikal yang memudahkan terjadinya pelarutan: $-\mathrm{COOH}$ atau $\mathrm{SO}_{3} \mathrm{H}$, dapat juga berupa kelompok pembentuk garam: - $\mathrm{NH}_{2}$ atau-OH. (Sastrawijaya, 1991).

Zat warna dapat digolongkan menurut sumber diperolehnya yaitu zat warna alam dan zat warna sintetik. Van Croft menggolongkan zat warna berdasarkan pemakaiannya, misalnya zat warna yang langsung dapat mewarnai serat disebutnya sebagai zat warna substantif dan zat warna yang memerlukan zatzat pembantu supaya dapat mewarnai serat disebut zat reaktif. Kemudian Henneck membagi zat warna menjadi dua bagian menurut warna yang ditimbulkannya, yakni zat warna monogenetik apabila memberikan hanya satu warna dan zat warna poligenatik apabila dapat memberikan beberapa warna. Penggolongan zat warna yang lebih umum dikenal adalah berdasarkan konstitusi (struktur molekul) dan berdasarkan aplikasi (cara pewarnaannya) pada bahan, misalnya didalam pencelupan dan pencapan bahan tekstil, kulit, kertas dan bahan-bahan lain. (Renita, dkk., 2004)

Penggolongan zat warna menurut "Colours Index" volume 3, yang terutama menggolongkan atas dasar sistem kromofor yang berbeda misalnya zat warna Azo, Antrakuinon, Ftalosia, Nitroso, Indigo, Benzodifuran, Okazin, Polimetil, Di- dan Tri-Aril karbonium, Polisiklik, Aromatik Karbonil, Quionftalen, Sulfer, Nitro, Nitrosol dan lain-lain. (Heaton, 1994)

Griffiths dan Daehne membagi pewarna berdasarkan tipe elektron - terangsang (exited) yang terjadi pada saat penyerapan cahaya. Luettke membaginya menjadi pewarna penyerap (absorption colorant), pewarna berfluorosensi (fluorescence colorant), dan pewarna pemindah daya (energy transfer colorant). (Pratikto, 2003) 


\section{Jurnal Keilmuan dan Aplikasi Teknik \\ UNISTEK, 2018, Edisi 5, No.1}

Zat warna termasuk spektrum yang luas dengan struktur kimia yang berbeda terutama didasarkan pada gugus utama yaitu golongan aromatik dan heterosiklik seperti gugus amina aromatik $\left(\mathrm{C}_{6} \mathrm{H}_{5}-\mathrm{NH}_{2}\right)$ yang dicurigai dapat menimbulkan penyakit kanker, phenil $\left(\mathrm{C}_{6} \mathrm{H}_{5}-\mathrm{CH}_{2}\right)$ dan naptil $\left(\mathrm{NO}_{2}-\mathrm{OH}\right)$. Hal yang paling umum adalah kemampuan zat kimia tersebut dalam penyerapan sinar cahaya tampak. (E. Lichtfouse, Et.al, 2005).

Dalam daftar "Color Index" golongan zat warna yang terbesar jumlahnya adalah zat warna dengan struktur azo yaitu sekitar $80 \%$. Dari zat warna yang berkromofor azo ini yang paling banyak digunakan dalam proses pencelupan bahan tekstil adalah zat warna reaktif. (Renita, dkk., 2004 dan A. Riga, Et.al, 2005).

Zat warna reaktif didefinisikan oleh Rys dan Zollinger sebagai campuran warna dimana mempunyai gugus stabil yang terbentuk dari ikatan kovalen antara atom karbon dan hidroksil serta amino yang dapat mengadakan reaksi adisi atau substitusi dengan gugus $\mathrm{OH}, \mathrm{SH}$ dan $\mathrm{NH}_{2}$ dalam serat. (Mansoor, 2008).

Menurut kelarutannya, ada zat dua jenis zat warna reaktif, yang larut dan terdispersi. Menurut cara bereaksinya dengan serat : yang mengadakan reaksi subtitusi dan reaksi adisi. Menurut fungsinya :ada zat warna monofungsional, bifungsional, dan multifungsional. Sedangkan menurut kandungan molekulnya : ada golongan azo, kompleks logam, antrakuinon, triphenodiaxazin dan golongan pthalosianin. Zat warna reaktif juga dibagi menjadi kontrol basa, kontrol garam, dan kontrol suhu. Zat warna reaktif molekulnya kecil seperti zat warna asam dan berwarna cerah. (Z Mbolekwa, 2008 dan Pratikto)

Disamping terjadinya reaksi antara zat warna dengan serat membentuk ikatan primer kovalen, ikatan pseudo ester atau eter, molekul air pun dapat mengadakan reaksi hidrolisa dengan molekul zat warna, dengan memberikan komponen zat warna yang tidak reaktif lagi. Reaksi hidrolisa tersebut akan bertambah cepat dengan kenaikan suhu. Agar dapat bereaksi zat warna memerlukan penambahan alkali yang berguna untuk mengatur suasana yang cocok untuk bereaksi, mendorong pembentukan ion selulosa dan menetralkan asam hasil reaksi zat warna reaktif dengan serat . (Renita, dkk., 2004).

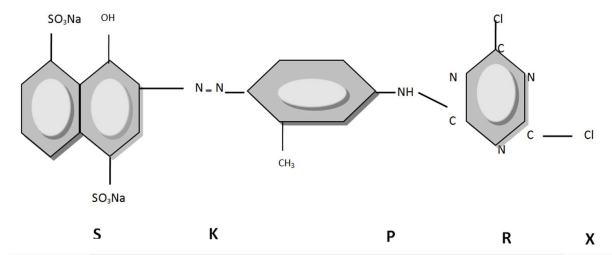

Gambar 1. Struktur Umum Zat Warna Reaktif
K : Kromofor, misalnya sistim yang mengandung gugus azo, antrakuinon, dan ftalosianin.

P : Gugus penghubung antara kromofor dan sistim reaktif, misalnya gugus amina, sulfo amina, dan amida.

R : Sistim Reaktif, misalnya triazin, pirimidin, vinil, dan kuinoksalin.

$\mathbf{X}$ : Gugus reaktif, mudah terlepas dari sistim reaktif, misal gugus khlor dan sulfat.

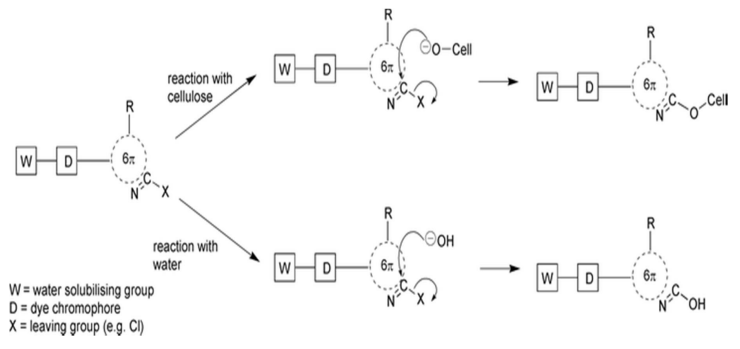

Gambar 2. Mekanisme Reaksi Zat Warna Reaktif

Zat warna reaktif C.I. Reactive Yellow 18 merupakan zat warna reaktif panas dengan struktur kimia monokhlorotriazina yang terdiri dari satu atau dua gugus khlor yang mempunyai kereaktifan rendah sehingga sangat ekonomis meskipun ada penambahan garam. Zat warna ini sangat cocok untuk digunakan pada serat selulosa seperti kapas, sutera, rayon, wol, rami, kertas, dan poliamida buatan. (Dystar, 2003 dan A. Riga, Et.al, 2005).

Nama C.I. Reactive Yellow 18 merupakan nama umum yang diambil dari Color Index sedangkan nama lainnya sangat banyak tergantung dari produsen, struktur, serta kegunaannya seperti CAS (Chemical Abstract Service) dengan nomor 12226-48-1, atau Reactive Brilliant Yellow K-4G, Cibacron Brilliant Yellow 2G-P, Procion Yellow H-4G, Amaryl Brilliant Yellow 4GX, Begative Yellow P-4G, Conreact Yellow AM, Sandalfix Yellow H4G, Viactive Yellow H4G, Na Intracron Brilliant Yellow 2G-P, Procion Brilliant Yellow $H-4 G$, atau dengan rumus langsung $\mathrm{C}_{25} \mathrm{H}_{16} \mathrm{ClN}_{9} \mathrm{O}_{13} \mathrm{~S}_{44}$

Procion Yellow $\mathrm{H}-4 \mathrm{G}$ adalah nama dagang C.I. Reactive Yellow 18 dari PT. Dystar. Huruf "H" menyatakan bahwa zat warna ini termasuk golongan $\mathrm{H}$ atau heat (panas), angka "4" menyatakan skala kecerahan dan kejenuhan warna, sedangkan huruf "G" berasal dari bahasa Jerman yaitu "gelb" yang berarti "kuning". Dalam aplikasinya, zat warna ini berwarna kuning lemon.

Struktur kimia zat warna ini belum dapat diketahui secara pasti karena menyangkut rahasia dari masing - masing produsen zat warna itu sendiri. Akan tetapi secara garis besar dapat diidentifikasi seperti gambar dibawah ini :

\section{Keterangan :}

S : Gugus Pelarut, misalnya asam sulfonat, karboksilat 


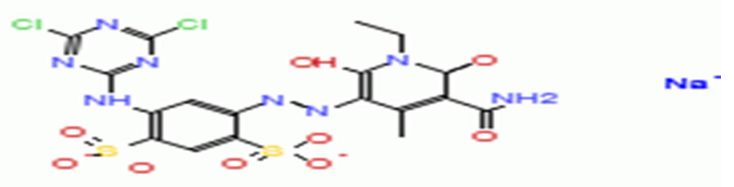

Gambar 3. Struktur zat warna reaktif

Teknologi pencelupan benang kapas dengan zat warna reaktif cara perendaman

Proses pemasukan zat warna ke dalam serat tekstil atau penempelan zat warna pada permukaan tekstil secara merata dengan bantuan air, uap air, dan udara kering. Pada proses pencelupan, larutan pencelupan terdiri dari zat warna, zat pembantu dan air sebagai media.

Pencelupan terdiri dari : melarutkan atau mendispersikan zat warna dalam air atau media lain, kemudian memasukkan bahan tekstil kedalam larutan tersebut sehingga terjadi penyerapan zat warna ke dalam serat. Penyerapan zat warna ke dalam serat merupakan suatu reaksi eksotermik dan reaksi kesetimbangan.

Beberapa zat pembantu seperti garam, asam, dan alkali atau yang lain nya ditambahkan ke dalam larutan celup untuk membantu proses penyerapan zat warna oleh serat, sehingga diperoleh warna yang diinginkan.

Vickerstaf menyimpulkan bahwa dalam pencelupan terjadi : difusi zat warna ke dalam larutan, adsorsi larutan zat warna dari larutan ke permukaan serat dan penetrasi atau difusi zat warna dari permukaan serat ke pusat serat. Gaya-gaya ikat pada pencelupan : ikatan hidrogen, ikatan kovalen, gayagaya non polar dan ikatan kovalen, setiap jenis zat warna mempunyai ketentuan sendiri-sendiri dalam cara pencelupannya, pencelupan bahan tekstil dapat dilakukan dalam bentuk serat, benang dan kain.

Pencelupan dalam bentuk benang dilakukan dengan tujuan agar kain yang dihasilkan nanti mempunyai corak tertentu, misalnya corak kotakkotak dan garis-garis pada kain sarung, kain kasur dan lain-lain. Dalam pencelupan benang selain dihasilkan warna yang sama dan merata pada permukaannya, juga dapat dihasilkan warna yang tidak merata.

Proses pencelupan dapat dilakukan : secara perendaman yang berdasarkan perbandingan larutan (vlot). Pemilihan jenis zat warna yang digunakan untuk mencelup bahan tekstil tergantung kepada : jenis serat yang akan dicelup, tahan luntur warna yang diinginkan serta faktor teknis dan ekonomis lainnya. Dalam praktek zat warna tekstil digolongkan berdasarkan : sifat-sifat pencelupannya, cara, dan penggunaannya, seperti : zat warna reaktif.

Benang yang digulung pada gulungan metal cone yang berlubang-lubang, sehingga memungkinkan keluar masuknya larutan zat warna dari setiap sisi benang gulung tersebut.
Teknik pencelupan : benang dalam bentuk gulungan dicelup dalam larutan yang mengandung zat warna reaktif dan zat pembantu pencelupan pada suhu, waktu dan vlot atau ratio tertentu, setelah selesai kemudian benang yang sudah dicelup tersebut dicuci dan disabun, untuk menghilangkan zat warna yang tidak terserap yang menempel pada permukaan bahan. Baik tidaknya hasil pencelupan, seperti kerataan warna dan daya tahan luntur warna yang ditentukan oleh proses pencelupannya dan proses yang dilalui sebelum bahan tersebut dicelup ( proses penyempurnaan awal).

Larutan zat warna yang bergerak dari dalam ke luar menyebabkan : mengendurnya gulungan benang sehingga lebih mudah zat warna yang bergerak dari luar ke dalam serat, menghasilkan tekanan yang merata ke gulungan-gulungan benang yang dicelup tersebut.

\section{Metodologi}

Metode yang dilakukan pada penelitian ini secara kuantitatif berdasarkan data yang diperoleh setelah melakukan eksperimen di laboratoriun PT. X di Tangerang dengan pola perlakuan sebagai berikut: Faktor A : Density gulungan benang, $\left(\mathrm{gr} / \mathrm{cm}^{3}\right)$

$$
\begin{array}{ll}
a_{1}: 0.28 \\
a_{2}: 0.32 \\
a_{3}: 0.36
\end{array}
$$

Faktor B : Waktu proses In-Out / Out-In, (menit)

\begin{tabular}{|c|c|c|c|c|c|}
\hline & & \multicolumn{3}{|c|}{$\begin{array}{c}\text { Waktu In-Out/Out-In } \\
\text { (menit) B } \\
\end{array}$} & \multirow[t]{2}{*}{$\begin{array}{c}\text { Total } \\
\left(\sum\right)\end{array}$} \\
\hline & & $\mathbf{b}_{1}$ & $\mathbf{b}_{2}$ & $\mathbf{b}_{3}$ & \\
\hline \multirow{9}{*}{$\begin{array}{l}\text { Density } \\
\text { Benang } \\
\left(\mathrm{gr} / \mathrm{cm}^{3}\right)\end{array}$} & \multirow{3}{*}{$\mathbf{a}_{1}$} & $\left(a_{1} b_{1}\right)_{1}$ & $\left(a_{1} b_{2}\right)_{1}$ & $\left(a_{1} b_{3}\right)_{1}$ & $\mathbf{Y}_{\mathbf{i}}$ \\
\hline & & $\left(a_{1} b_{1}\right)_{2}$ & $\left(a_{1} b_{2}\right)_{2}$ & $\left(a_{1} b_{3}\right)_{2}$ & $Y_{i}$ \\
\hline & & $\left(a_{1} b_{1}\right)_{3}$ & $\left(a_{1} b_{2}\right)_{3}$ & $\left(a_{1} b_{3}\right)_{3}$ & $Y_{i}$ \\
\hline & \multirow{3}{*}{$\mathbf{a}_{2}$} & $\left(a_{2} b_{1}\right)_{1}$ & $\left(a_{2} b_{2}\right)_{1}$ & $\left(a_{2} b_{3}\right)_{1}$ & $\mathbf{Y}_{\mathbf{i}}$ \\
\hline & & $\left(a_{2} b_{1}\right)_{2}$ & $\left(a_{2} b_{2}\right)_{2}$ & $\left(a_{2} b_{3}\right)_{2}$ & $\mathbf{Y}_{\mathrm{i}}$ \\
\hline & & $\left(a_{2} b_{1}\right)_{3}$ & $\left(a_{2} b_{2}\right)_{3}$ & $\left(a_{2} b_{3}\right)_{3}$ & $\mathbf{Y}_{\mathrm{i}}$ \\
\hline & \multirow{3}{*}{$\mathbf{a}_{3}$} & $\left(a_{3} b_{1}\right)_{1}$ & $\left(a_{3} b_{2}\right)_{1}$ & $\left(a_{3} b_{3}\right)_{1}$ & $\mathbf{Y}_{\mathrm{i}}$ \\
\hline & & $\left(a_{3} b_{1}\right)_{2}$ & $\left(a_{3} b_{2}\right)_{2}$ & $\left(a_{3} b_{3}\right)_{2}$ & $\mathbf{Y}_{\mathrm{i}}$ \\
\hline & & $\left(a_{3} b_{1}\right)_{3}$ & $\left(a_{3} b_{2}\right)_{3}$ & $\left(a_{3} b_{3}\right)_{3}$ & $\mathbf{Y}_{\mathbf{i}}$ \\
\hline \multicolumn{2}{|c|}{ Total $(\Sigma)$} & $\mathbf{Y}_{\mathbf{j}}$ & $Y_{j}$ & $\mathbf{Y}_{\mathrm{j}}$ & \\
\hline
\end{tabular}

$$
\begin{aligned}
& \mathrm{b}_{1}: \text { In-Out } 1 / \text { Out-In } 2 \\
& \mathrm{~b}_{2}: \text { In-Out } 2 / \text { Out-In } 3 \\
& \mathrm{~b}_{3}: \text { In-Out } 3 \text { / Out-In } 3
\end{aligned}
$$

Tabel 1. Desain eksperimen

\section{Variabel Penelitian}

Pada penelitian ini terdapat dua variabel, yakni variabel bebas dan variabel terikat. Variabel bebas (X) adalah variabel yang menjadi sebab perubahan dan akan mempengaruhi variabel terikat, variabel bebas pada penelitian ini meliputi dua variabel, yakni : Density gulungan benang $\left(\mathrm{X}_{2}\right)$, dan Waktu proses InOut / Out-In $\left(\mathrm{X}_{1}\right)$. Variabel terikat $(\mathrm{Y})$ adalah variabel yang dipengaruhi oleh variabel bebas. Dalam 
penelitian ini variabel terikatnya Kerataan warna hasil pencelupan

\section{Metode Pengumpulan Data}

Setelah mendapatkan bahan benang berwarna hasil percobaan dari perlakuan proses dengan memvariasikan density gulungan benang dan waktu proses in-out / out-in., seluruh bahan dari hasil percobaan di uji kerataan warnanya dengan alat spectrofotometri. Data yang didapat dari hasil pengujian itulah yang akan gunakan untuk pembuktian hipotesis penelitian, namun sebelumnya dilakukan uji validitas dan reliabilitas terlebih dahulu. Setelah data dihitung maka akan menghasilkan kesimpulan bahwa variabel penelitian tersebut dinyatakan valid dan reliabel atau tidak sama sekali, selain itu juga dilakukan perhitungan dengan menggunakan uji-T, uji-F dan koefisien determinasi $\left(\mathrm{R}^{2}\right)$

\section{Uji Validitas dan Reliabilitas}

Uji validitas dan uji reliabilitas dapat dijabarkan sebagai berikut (Iskandar, 2013):

1. Uji validitas dilakukan untuk mengetahui apakah data yang dipergunakan benar-benar mampu mengukur atau menguji dengan valid dan diketahui kebenarannya.

2. Uji reliabilitas bertujuan untuk mengetahui apakah data yang dipergunakan menunjukkan tingkat ketepatan, keakuratan, kestabilan, atau konsistensi. Dengan kata lain sejauh mana data hasil uji dengan alat spectrofotometri tetap konsisten jika dilakukan pengukuran dua kali atau lebih terhadap masalah yang sama.

\section{Uji Hipotesis}

Uji hipotesis penelitian ini menggunakan uji-T uji-F serta koefisien diterminasi $\left(\mathrm{R}^{2}\right)$ dengan uji dua arah dan tingkat signifikansi ( $\alpha$ ) sebesar 5\%.

1. Uji-T atau uji statistik $\mathrm{T}$ pada dasarnya menunjukkan seberapa jauh pengaruh satu variabel bebas secara individual dalam menerangkan variasi variabel terikat.

2. Uji_F atau uji statistik $F$ digunakan untuk menentukan apakah secara bersam-sama variabel terikat mampu menjelaskan variabel bebas dengan baik, atau apakah variabel terikat mempunyai pengaruh yang signifikan terhadap variabel bebas.

3. Koefisien determinasi $\left(\mathrm{R}^{2}\right)$ digunakan untuk mengetahui berapa persen variasi variabel bebas dapat dijelaskan oleh variabel terikat. Jika $\left(\mathrm{R}^{2}\right)$ mendekati 1 maka terdapat pengaruh yang sangat kuat dan jika mendekati 0 berarti memiliki

\section{Hasil dan Pembahasan \\ Hasil uji kuantitatif}

Data hasil eksperimen. Untuk mempermudah dalam pengolahan data dari seluruh perlakuan, maka disusun tabel sebagai berikut :
Tabel 2. Data Hasil Eksperimen

Waktu In - Out / Out - In (Menit )

B

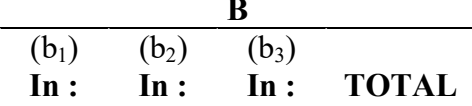

1/ 2/ 3/

( $\Sigma)$

Out : Out : ${ }_{3}$ Out :

\begin{tabular}{|c|c|c|c|c|c|}
\hline & & 0.38 & 020 & 0.45 & - \\
\hline & $\left(a_{1}\right)$ & & & & \\
\hline & 0.28 & 0.39 & 0.21 & 0.44 & - \\
\hline & & 0.41 & 0.26 & 0.50 & - \\
\hline & $\begin{array}{c}\text { Sub } \\
\text { Total }\end{array}$ & 1.18 & 0.67 & 1.39 & 3.240 \\
\hline $\begin{array}{l}\text { Density } \\
\text { Benang }\end{array}$ & $\begin{array}{c}\text { Rata- } \\
\text { rata }\end{array}$ & 0.394 & 0.224 & 0.464 & 0.361 \\
\hline & & 0.26 & 0.15 & 0.27 & - \\
\hline $\mathbf{A}$ & $\begin{array}{c}\left(a_{1}\right) \\
0.32\end{array}$ & 0.18 & 0.14 & 0.28 & - \\
\hline & & 0.27 & 0.14 & 0.30 & - \\
\hline & $\begin{array}{c}\text { Sub } \\
\text { Total }\end{array}$ & 0.71 & 0.43 & 0.85 & 1.990 \\
\hline & $\begin{array}{c}\text { Rata- } \\
\text { rata }\end{array}$ & 0.237 & 0.143 & 0.284 & 0.222 \\
\hline & $\left(a_{1}\right)$ & 0.52 & 0.30 & 0.86 & - \\
\hline & 0.36 & 0.55 & 0.31 & 0.83 & - \\
\hline & & 0.71 & 0.31 & 0.79 & - \\
\hline & $\begin{array}{c}\text { Sub } \\
\text { Total }\end{array}$ & 1.78 & 0.92 & 2.48 & 5.180 \\
\hline & $\begin{array}{c}\text { Rata- } \\
\text { rata }\end{array}$ & 0.594 & 0.307 & 0.827 & 0.576 \\
\hline TOTA & $(\Sigma)$ & 3.670 & 2.020 & 4.720 & 10.410 \\
\hline RATA- & ATA & 0.409 & 0.225 & 0.525 & - \\
\hline
\end{tabular}

\section{Pembahasan}

Setelah dilakukan uji validitas dengan korelasi pearson, dan uji reliabilitas dengan Alpha Cronbach, setelah dinyatakan masing-masing variabel valid dan nilai alpha diatas 0.7 artinya reliabelitas atau tingkat kepercayaan telah mencukupi, sehingga secara umum data dapat dipercaya. Uji T menunjukkan bahwa ada perbedaan antara nilai variabel bebas dengan nilai variabel terikat. Dan terdapat perbedaan yang signifikan antara variabel berdasarkan perhitungan artinya terdapat korelasi yang linear antara Density gulungan benang (X1), Waktu proses In-Out / Out-In (X2) terhadap Kerataan warna hasil pencelupan benang kapas dengan zat warna reaktif cara perendaman.

Uji $F$ digunakan untuk menentukan apakah secara bersama-sama variabel terikat mampu menjelaskan variabel bebas dengan baik atau apakah variabel terikat mempunyai pengaruh yang signifikan terhadap variabel bebas. 
Untuk membuktikan apakah hipotesa diterima atau ditolak maka dilakukan perhitungan analisis sebagai berikut:

Tabel 3. Analisis

\begin{tabular}{ccccccc}
\hline & & & & & & \\
$\begin{array}{c}\text { Ke- } \\
\text { ragaman }\end{array}$ & db & JK & KT & F $_{\text {hit. }}$ & \multicolumn{2}{c}{ F $_{\text {tabel }}$} \\
\cline { 5 - 7 } & & & & & & \\
\hline $\begin{array}{c}\text { Per- } \\
\text { lakuan }\end{array}$ & 5 & 9.33 & - & - & 3.11 & 5.06 \\
\hline A & 1 & 14.3 & 14.3 & 16.85 & 4.75 & 9.33 \\
\hline B & 2 & 30.81 & 15.40 & 18.12 & 3.88 & 6.93 \\
\hline AB & 2 & 23.05 & 11.52 & 13.56 & 3.88 & 6.93 \\
\hline Galat & 4 & 10.20 & 0.85 & - & - & - \\
\hline Total & 17 & 0.87 & - & - & - & - \\
\hline & & & & & & \\
\hline
\end{tabular}

Kemudian dilakukan pengujian terhadap hipotesis dimana hipotesis $\mathrm{A}, \mathrm{B}$, dan $\mathrm{AB}$ serta pengambilan keputusan dilakukan dengan menggunakan Faktor Hitung $\left(\mathrm{F}_{\text {hit. }}\right)$. Dari hasil perhitungan tersebut dapat diambil suatu kaidah keputusan, dengan membandingkan antara $\left(\mathrm{F}_{\text {hit. }}\right)$, dengan $\left(\mathrm{F}_{\text {tab }}\right)$.

Perlakuan (A), density gulungan benang hasil uji statistik di dapat faktor $F_{\text {hit }}(16.85)>F_{\text {tab }}$ (4.75), kesimpulan analisis berbeda nyata (significant), berarti perlakuan (A), memberikan pengaruh nyata terhadap kerataan warna hasil celupan benang kapas dengan zat warna reaktif cara perendaman. Karena makin tinggi density gulungan $0.36 \mathrm{~g} / \mathrm{cm}^{3}$, penyerapan larutan zat warna ke dalam serat makin sulit atau tidak lancar tetapi makin rendah density gulungan $0.28 \mathrm{~g} / \mathrm{cm}^{3}$ penerapan makin mudah tetapi akan merusak gulungan benang karena tekanan larutan zat warna. Sehingga akan berdampak tidak ratanya hasil pencelupan. Dengan density gulungan benang yang optimum yaitu $0.32 \mathrm{~g} / \mathrm{cm}^{3}$, penyerapan zat warna dalam benang baik, sehingga hasil pencelupan rata.

Perlakuan (B), waktu proses pencelupan hasil uji statistik di dapat faktor $F_{\text {hit }}(18.12)>F_{\text {tab }}$ (3.88), kesimpulan analisis berbeda nyata (significant), berarti perlakuan (B), memberikan pengaruh nyata terhadap kerataan warna hasil celupan benang kapas dengan zat warna reaktif cara perendaman. Dengan watu pencelupan yang singkat $1: 2$ kesempatan zat warna untuk berfiksasi, bermigrasi lalu bereaksi makin kecil sedang makin lama waktu pencelupan 3 : 3 tidak diperlukan, karena berfiksasinya zat warna kedalam serat ada batas waktu yang optimum, karena pencelupan merupakan reaksi kesetimbangan, jadi dengan memperpanjang waktu pencelupan tidak akan menambah jumlah zat warna yang berfiksasi dengan benang. Karena tempat atau molekul serat dalam benang yang dapat mengadakan reaksi dengan zat warna sudah semua bereaksi, sehingga penyerapan zat warna akan berhenti.

Interaksi perlakuan (A), density gulungan benang, dan perlakuan (B), waktu proses pencelupan, hasil uji statistik faktor $F_{\text {hit }}(13.56)>$ $\mathrm{F}_{\text {tab }}$ (3.88), kesimpulan analisis berbeda nyata (significant), berarti interaksi perlakuan (A), dan perlakuan (B) memberikan pengaruh nyata terhadap kerataan warna hasil celupan benang kapas dengan zat warna reaktif cara perendaman.

Diterminasi, Koefisien determinasi digunakan untuk mengetahui berapa persen variasi variabel bebas dapat dijelaskan oleh variabel terikat. Jika nilai $\mathrm{R}^{2}$ mendekati 1 maka terdapat pengruh yang sangat kuat, dari hasil perhitungan diperoleh nilai diterminasi $\mathrm{R}^{2}=$ 0.7284 yang berarti pengaruh variabel bebas density gulungan benang $\left(\mathrm{X}_{1}\right)$, Waktu proses InOut / Out-In $\left(\mathrm{X}_{2}\right)$ berkorelasi linear terhadap variabel terikat Kerataan warna hasil pencelupan (Y)

\section{Kesimpulan}

Berdasarkan pengolahan data secara statistik, secara kunatitatif menunjukkan korelasi linear yang signifikan antara density gulungan benang $\left(\mathrm{X}_{1}\right)$, Waktu proses In-Out / Out-In $\left(\mathrm{X}_{2}\right)$ terhadap Kerataan warna hasil pencelupan (Y).

\section{Saran}

Berdasarkan kesimpulan tersebut diatas saran yang dapat diajukan :

1. Density gulungan benang $0.32 \mathrm{~g} / \mathrm{cm}^{3}$, menunjukkan hasil terbaik dalam hal kerataan warna hasil celupan benang kapas dengan zat warna reaktif cara perendaman. Dapat menjadi bahan pertimbangan dalam proses pencelupan benang dalam bentuk gulungan.

2. Waktu proses pencelupan (in : 2 menit / out : 3 menit), menunjukkan hasil terbaik dalam hal kerataan warna hasil celupan benang kapas dengan zat warna reaktif cara perendaman. Sehingga dapat menjadi bahan pertimbangan dalam proses pencelupan benang dalam bentuk gulungan.

3. Density gulungan benang $0.32 \mathrm{~g} / \mathrm{cm}^{3}$, dan waktu proses pencelupan (in : 2 menit / out : 3 menit), menunjukkan hasil terbaik dalam hal kerataan warna hasil celupan benang kapas dengan zat warna reaktif cara perendaman. Dapat menjadi bahan pertimbangan dalam proses pencelupan benang dalam bentuk gulungan.

4. Dilakukan penelitian lanjut untuk mengetahui faktor lain yang berpengaruh dalam proses 


\section{Jurnal Keilmuan dan Aplikasi Teknik \\ UNISTEK, 2018, Edisi 5, No.1}

pencelupan benang kapas dalam bentuk gulungan yang tidak diteliti dalam penelitian ini.

\section{Daftar Pustaka}

Alaerts, G. \& Sumestri, S.S. (1987). Metode Penelitian Air. Surabaya: Usaha Nasional

Astini, S. (1972). Pedoman Praktikum Pengelantangan dan Pencelupan, Bandung: ITT.

Beech. (1972). Fibre Reactif Dyes. ICI

Blackburn, R.S. \& Burkinshaw, S.M. (2002). A Greener Approach to Cotton Dyeings With Excellent Wash Fastness. UK : University of Leeds.

Blackburn, R.S. (2006). New Green Chemical Techniques in Textile Coloration Processes. UK : University of Leeds.

Darmojo, H.S. (2010). Teknologi Pencelupan Terapan. Tangerang: FT Unis Tangerang

Dystar. (2003). Remazol ${ }^{\circledR} \quad$ Levafix ${ }^{\circledR} \quad$ Procion $\AA$ Sirius ${ }^{\circledR}$ Product Overview of Reactive and Direct Dyes.

Fessenden, R.J. \& Fessenden, J.S. (1994). Kimia Organik. Jakarta : Erlangga

Gaspersz, V. (1994). Metode Perancangan Percobaan. Bandung : CV. Armico

Hart, H. (1990). Kimia Organik. Suatu Kuliah Singkat Edisi Keenam Terjemah. Jakarta : Erlangga

Heaton, A. (1994). The Chemical Industry, Second edition. London : Blackie Academic and Profesional, Chapman \& Hal.

Iqbal, M. (2008). Textile Dyes. Pakistan : Rehbar Publisher

Isminingsih \& Rasjid, D. (1982). Pengantar Kimia Zat Warna. Bandung : Institut Teknologi Tekstil

Isminingsih, G. (1978). Pengantar Kimia zat warna. Bandung: ITT

Manurung, R. dkk. (2004). Perombakan Zat Warna Azo Reaktif Secara Anaerob - Aerob. Medan : FT - T. Kimia, Universitas Sumatera Utara

Marmagne, O. \& dan Coste, C. (1996). Color Removal From Textile Plant Effluent. Perancis : Degremont S.A.

Petrucci, R.H. (1993). Kimia Dasar, Prinsip dan Terapan Modern. Jakarta : Erlangga

Pratikto, E. (2003). Kimia Zat Warna. Tangerang: FT - Teknik Kimia Tekstil Unis Tangerang.

Rasyid, J. (1976). Teknologi Pengelantangan, Pencelupan dan Pencapan, Bandung: ITT

Saepudin, S. (1998). Penyerapan Zat Warna Tekstil BR Red HE $7 B$ Oleh Jerami Padi. Bandung : Institut Teknologi Bandung

Soedarsono \& Syahputra, B. (2005). Pengolahan Air Limbah Batik Dengan Proses Kombinasi Elektrokimia, Filtrasi, dan Adsorbsi. Semarang : FT-TL Universitas Islam Sultan Agung (UNISSULA)

Sukardjo. (1990). Kimia Anorganik. Jakarta : Rineka Cipta
Supriyono, P. (1974). Serat - serat Tekstil, Bandung: ITT

Sykes, P. (1989). Penuntun Mekanisme Reaksi Kimia Organik Edisi Keenam Terjemah. Jakarta : Gramedia

Trotman, E.R. (1975). Dyeing and Chemical Tecnologi of Textile Fibre, London.

Watanabe, S. \& Hartanto, N.S. (1986). Teknologi Tekstil. Jakarta: Pradnya Paramita. 
Jurnal Keilmuan dan Aplikasi Teknik

UNISTEK, 2018, Edisi 5, No.1 